Vol.1 No.1. April 2019. pp.51-57.Copyright@2019 PUBLICUHO Faculty of Social and Political Sciences Halu Oleo University, Kendari, Southeast Sulawesi, Indonesia.e-ISSN: 2621-1351. Open Access at:

http://ojs.uho.ac.id/index.php/PUBLICUHO

Jounal publiuho is licensed under a Creative Commons Attribution 4.0 International License, which permits unrestricted use, distribution, and reproduction in any medium, provided the original work is properly cited.

\title{
Evaluasi Program CSR (Corporate Social Responsibility) Perusahaan PT. ANTAM Tbk UBPN SULTRA Kecamatan Pomalaa Kabupaten Kolaka (Studi Kasus Desa Tambea)
}

\author{
Oleh: \\ Theofilus $S^{1}$, Irfan $\operatorname{Ido}^{2}$, Suryawan $\bar{A}^{3}$ \\ ${ }^{1}$ Mahasiswa, ${ }^{2,3}$ Dosen Jurusan FITK Universitas Halu Oleo \\ Theofilussalea@gmail.com
}

\begin{abstract}
TPT. ANTAM Tbk is a company engaged in the exploration of mining materials such as nickel, gold and silver, and bauxite. Tambea village is one of the areas in Pomalaa Subdistrict, Kolaka Regency, which is close to PT. ANTAM Tbk. The purpose of this study can evaluate the CSR program of PT. ANTAM Tbk in Tambea Village, Pomalaa District, Kolaka Regency. The method of determining the sample uses the System of Rise Intensification method with a population of 24 heads of households as respondents. The analytical method used to determine the relationship between level of performance and level of expectation is the method of IPA analysis (Importance Performance Analysis). The results of this study indicate that the company PT. ANTAM Tbk still has to improve its performance on the elements of program distribution and supporting elements of the program.
\end{abstract}

Keywords : Evaluation, CSR Program and company PT. ANTAM Tbk.

\section{PENDAHULUAN}

Di Indonesia secara general sudah banyak perusahaan yang menerapkan program-program CSR. Salah satunya adalah PT. Aneka Tambang (selanjutnya disingkat Antam) merupakan salah satu Badan Usaha Milik Negara (selanjutnya disingkat BUMN) yang bergerak dalam eksplorasi bahan-bahan tambang seperti nikel, emas dan perak, serta bauksit. Kegiatan operasi PT. Antam inilah yang menjadi salah satu penopang perekonomian Provinsi Sulawesi Tenggara mengingat banyaknya anggaran yang dikeluarkan PT. Antam dalam membantu program-program Pemerintah Sulawesi Tenggara untuk mengembangkan masyarakat disekitarnya. Corporate Social Responsibility merupakan kewajiban suatu perusahaan yang seyogyanya dilaksanakan demi meredam ketidakpuasan masyarakat. Tidak ada perusahaan yang ingin ditutup paksa oleh masyarakat. Sebaliknya pimpinan perusahaan menginginkan masyarakat sebagai mitra kerja, dan mitra pelindung sejati. Oleh sebab itu pimpinan perusahaan wajib rela mengalokasikan sebagian pendapatan lebih untuk dialokasikan sebagian pendapatan lebih untuk dialokasikan pada CSR (Corporate Social Responsibility). Salah satu ukuran keberhasilan CSR adalah bila masyarakat yang dibantu bisa mandiri. Dengan demikian "pagar pelindung" perusahaan semakin kokoh. Pada dasarnya, tujuan utama dari pendirian perusahaan adalah mencari profit. Dalam menjalankan aktivitas bisnisnya untuk mencapai tujuan (profit), perusahaan diharapkan untuk memperhatikan dampak lingkungan yang ditimbulkan serta dapat memberi kontribusi untuk masyarakat di sekitarnya. Peran CSR dalam hal ini adalah untuk menyelaraskan dan menyeimbangkan dampak-dampak yang ditimbulkan dari keberadaan sebuah perusahaan PT ANTAM Tbk dalam (www.antam.com/), percaya bahwa pertumbuhan dan kemajuan yang dicapai oleh Perusahaan sudah selayaknya berjalan seiring dengan kesejahteraan masyarakat, khususnya yang berada di sekitar daerah operasi. Salah satu upaya untuk melakukan hal tersebut adalah dengan mengoptimalkan implementasi Program Kemitraan dan Bina 
Lingkungan (PKBL) yang tujuannya agar mendorong kesejahteraan dan kemandirian masyarakat, Program Kemitraan ini di berikan dalam bentuk modal usaha, pendampingan, dan pelatihan kepada masyarakat.

Dalam lingkungan perusahaan, masyarakat di sekitar perusahaan merupakan pihak yang terpenting untuk memperoleh apresiasi. Apresiasi itu sendiri dapat berbentuk peningkatan kesejahteraan hidup melalui kegiatan pemberdayaan masyarakat yang dilakukan oleh perusahaan melalui kegiatan CSR. Dalam penerapannya, umumnya perusahaan akan melibatkan partisipasi masyarakat, baik sebagai objek maupun sebagai subjek program CSR. Hal ini dikarenakan masyarakat adalah salah satu pihak yang cukup berpengaruh dalam menjaga eksistensi suatu perusahaan. Masyarakat adalah pihak yang paling merasakan dampak dari kegiatan produksi suatu perusahaan, baik itu dampak positif ataupun negatif. Dampak ini dapat terjadi dalam bidang sosial, ekonomi, politik maupun lingkungan.

\section{METODE PENELITIAN}

Penelitian ini dilaksanakan di Desa Tambea Kecamatan Pomalaa Kabupaten Kolaka. Lokasi penelitian ini dipilih dengan alasan bahwa lokasi penelitian ini merupakan desa lingkar tambang PT. ANTAM Tbk.

\section{Tahapan Penelitian}

Adapun tahapan yang dilakukan dalam penelitian ini, meliputi:

a. Observasi, yaitu data dikumpulkan melalui pengamatan langsung terhadap obyek penelitian.

b. Wawancara terstruktur, yaitu melakukan tanya jawab dengan obyek penelitian untuk mengumpulkan data dan informasi yang diperlukan dengan menggunakan kuesioner yang telah disiapkan sebelumnya.

Penentuan sampel dilakukan secara sensus, yaitu seluruh masyarakat yang mendapatkan bantuan CSR PT. Antam berupa alat tangkap ikan. Hal ini didasarkan atas pendapat, bahwa apabila jumlah populasi kurang dari 50 orang, maka sebaiknya diambil seluruhnya sebagai sampel penelitian.

\section{Analisis dan Pengolahan Data}

Berdasarkan data primer dan data sekunder yang diperoleh, maka selanjutnya data diolah dengan menggunakan pendekatan analisis secara deskriptif kualitatif. Hasil pengumpulan dta tersebut kemudian dianalisis menggunakan Importance Performance Analysis (IPA). dengan Bobot rata-rata tingkat penilaian persepsi variabel ke-i, Bobot rata-rata tingkat penilaian harapan variabel ke-i, dan n Jumlah responden.

Setelah diperoleh bobot tingkat kinerja dan tingkat kepentingan variabel serta nilai rata-rata tingkat kinerja dan tingkat kepentingan variabel, kemudian nilai-nilai tersebut diplotkan kedalam diagram kartesius seperti ditunjukan pada gambar berikut :

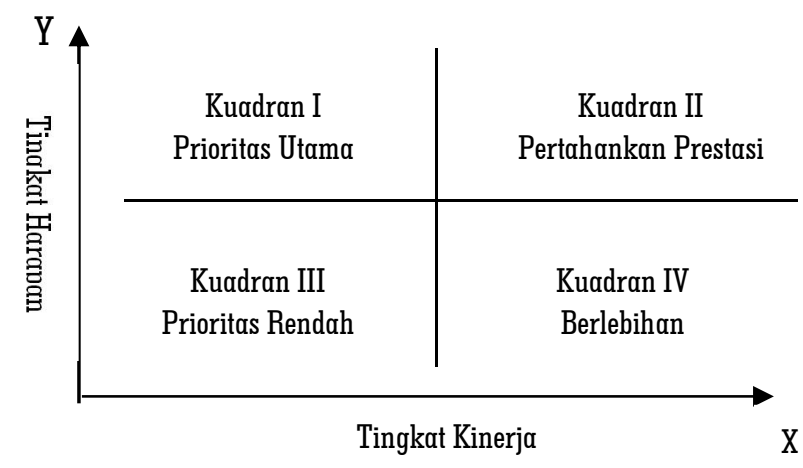

Gambar 1. Kuadran Expe ctation-Performance Analysis

Penjelasan mengenai empat kuadran adalah sebagai berikut:

1. Kuadran I (prioritas utama) ini membuat variabel-variabel implementasi CSR yang dianggap penting oleh masyarakat tetapi pada kenyataannya variabel-variabel tersebut memiliki tingkat kinerja yang belum 
Jounal publiuho is licensed under a Creative Commons Attribution 4.0 International License, which permits unrestricted use, distribution, and reproduction in any medium, provided the original work is properly cited.

sesuai dengan tingkat kepentingan masyarakat. Tingkat kinerja dari variabel tersebut lebih rendah daripada tingkat kepentingan masyarakat terhadap varaibel tersebut. Variabel-variabel yang terdapat dalam kuadran ini harus lebih ditingkatkan lagi kinerjanya agar dapat memuaskan masyarakat setempat.

2. Kuadran II (pertahankan prestasi) variabel-variabel yang terdapat dalam kuadran ini menunjukan bahwa variabel tersebut paling penting dan memiliki kinerja tinggi. Variabel ini perlu dipertahankan untuk waktu selanjutnya.

3. Kuadran III (prioritas rendah) variabel yang terdapat dalam kuadran ini dianggap kurang penting oleh masyarakat dan pada kenyataannya kinerjanya tidak terlalu istimewa. Peningkatan terhadap variabel yang masuk dalam kuadran ini dapat dipertimbangkan kembali pengaruhnya terhadap manfaat yang dirasakan oleh masyarakat sangat kecil.

4. Kuadran IV (berlebihan) kuadran ini membuat variabel-variabel yang dianggap kurang penting oleh masyarakat dan dirasakan terlalu berlebihan Peningkatan kinerja variabel-variabel yang terdapat pada kuadran ini hanya akan menyebabkan terjadinya pemborosan sumber daya.

\section{PEMBAHASAN}

\section{Unsur Program CSR yang dievaluasi}

\section{a. Sosialisasi sebelum program}

Berdasarkan hasil wawancara dengan beberapa responden di Desa Tambea didapatkan data dan dianalisis menggunakan

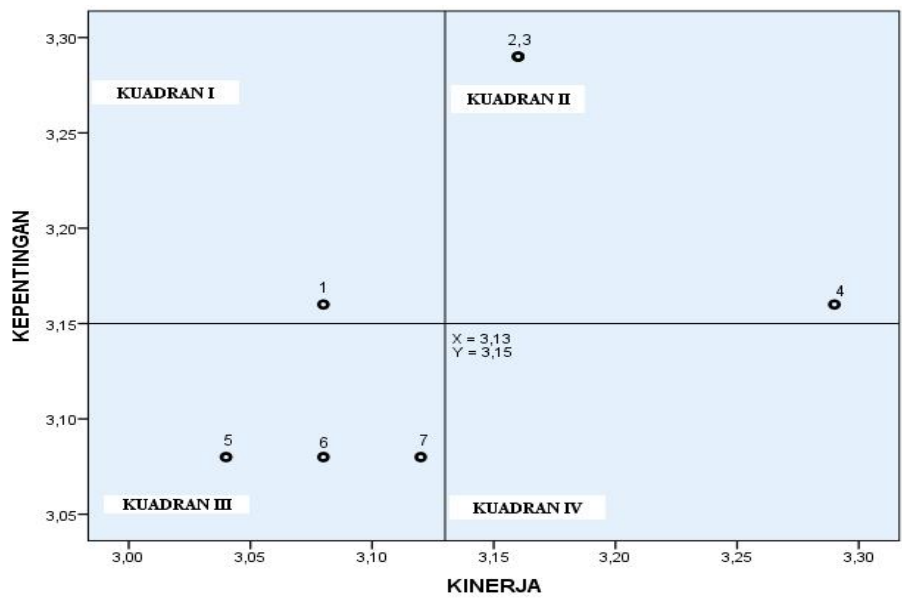

Gambar 2. Diagram Kartesius sosialisasi sebelum program

Variabel yang termasuk dalam kuadran ini adalah kejelasan informasi mengenai prosedur untuk bisa menerima bantuan dan kesesuaian kebutuhan masyarakat dengan sosialisasi program oleh pihak perusahaan.

Kuadran II variabel ini harus dipertahanan karena sangat penting dan memiliki tingkat kinerja yang tinggi sehingga variabel ini bisa dijalankan atau dipertahankan untuk waktu selanjutnya.

Kuadran III (prioritas rendah), merupakan hal yang dianggap kurang penting oleh masyaraat karena tingkat kinerjanya tidak terlalu istimewa atau variabel yang termaksud dalam kuadran ini harus di tingkatkan dan dikontrol karena tingkat harapan masyarakat dapat berubah seiring meningkatnya kebutuhan. Variabel yang termasuk dalam kuadran ini adalah kejelasan informasi mengenai prosedur untuk berpatisipasi dalam pelasanaan program, kejelasan informasi awal mengenai program CSR dan Kejelasan informasi mengenai persyaratan untuk bisa berpartisipasi.

\section{b. Proses Penyaluran Program}

Proses penyaluran program berupa bantuan mesin kapal disalurakan pada tahun 2016. Pihak perusahan menyalurkan langsung bantuan ini dan disaksikan oleh aparat desa setempat. 
Berikut ini tabel tanggapan responden tentang proses penyaluran progam CSR di Desa Tambea. Dapat kita lihat pada Tabel 1 .

Tabel l. Rata-rata tingkat kinerja dan tingkat kepentingan

\begin{tabular}{|c|c|c|}
\hline No & $\begin{array}{c}\text { Rata-rata nilai tingat } \\
\text { kineja }\end{array}$ & $\begin{array}{c}\text { Rata-rata nilai tingkat } \\
\text { kepentingan }\end{array}$ \\
\hline 1 & 2.83 & 3.12 \\
\hline 2 & 3.16 & 3.33 \\
\hline 3 & 3.04 & 3.04 \\
\hline 4 & 2.70 & 3.25 \\
\hline 5 & 3,04 & 3.25 \\
\hline 6 & 3,00 & 3.08 \\
\hline
\end{tabular}

Sumber: Hasil Penelitian, 2016

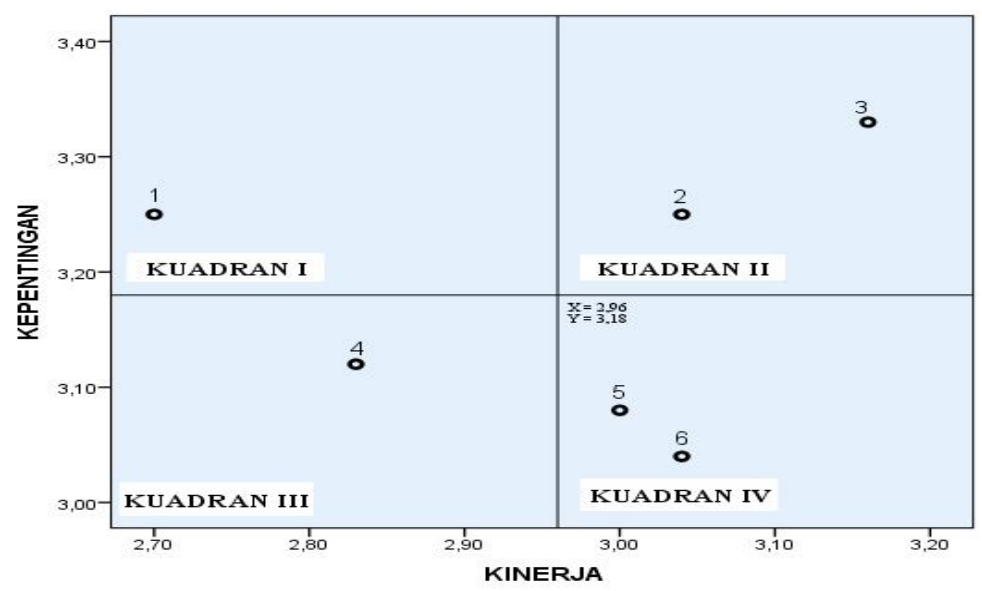

Gambar 3. Diagram kartesius proses penyaluran program

Kuadran I (prioritas utama) variabel ini harus ditingkatkan kinerjanya karena ini dianggap sangat penting bagi masyarakat yang mendapatkan bantuan berupa mesin tangakap ikan.Kuadran II (pertahanan prestasi) ada dua hal yang harus dipertahanan pihak perusahaan yaitu kesesuaian jenis program yang diberikan dengan jenis bantuan yang dibutuhkan warga dan kemudahan mengurus permohonan memperoleh program CSR. Menurut masyarakat, hal-hal seperti ini harusnya dipertahankan perusahaan agar variabel ini bisa dilanjutkan untuk program selanjutnya.

Untuk kuadran III (prioritas rendah) Variabel kemudahan memenuhi persyaratan program CSR inilah yang dianggap kurang penting oleh masyarakat Desa Tambea karena semua bantuan yang ada tidak memerlukan persyaratan yang khusus. Pada proses penyaluran program ada beberapa variabel yang termasuk dalam kuadran IV (berlebihan). Variabel kesesuaian jenis program yang diterapan dengan jenis bantuan yang dibutuhan warga dan kemudahan prosedur untuk berpartisipasi dalam pelaksanaan progam harusnya dihapuskan saja dan digantikan dengan variabel-variabel yang lebih dibutuhkan masyarakat.

\section{c. Jadwal dan Jenis Program}

adwal dan jenis program adalah konsistensi waktu antara berbagai jenis pelaksanaan program yang telah direncanakan dan disepakati bersama masyarakat penerima program CSR PT. Aneka Tambang Tbk.

Kemudian, dapat dilihat nilai rata-rata tingat kinerja dan tingkat kepentingan dari jawaban responden pada tabel dibawah ini. 
Tabel 2. Nilai rata-rata tingkat kinerja dan tingkat kepentingan

\begin{tabular}{|c|c|c|}
\hline No & Nilai rata-rata tingkat kinerja & Nilai rata-rata tingkat kepentingan \\
\hline 1 & 2,79 & 3,37 \\
\hline 2 & 2,95 & 3,20 \\
\hline 3 & 3,12 & 3,20 \\
\hline
\end{tabular}

Sumber: Hasil Penelition, 2016

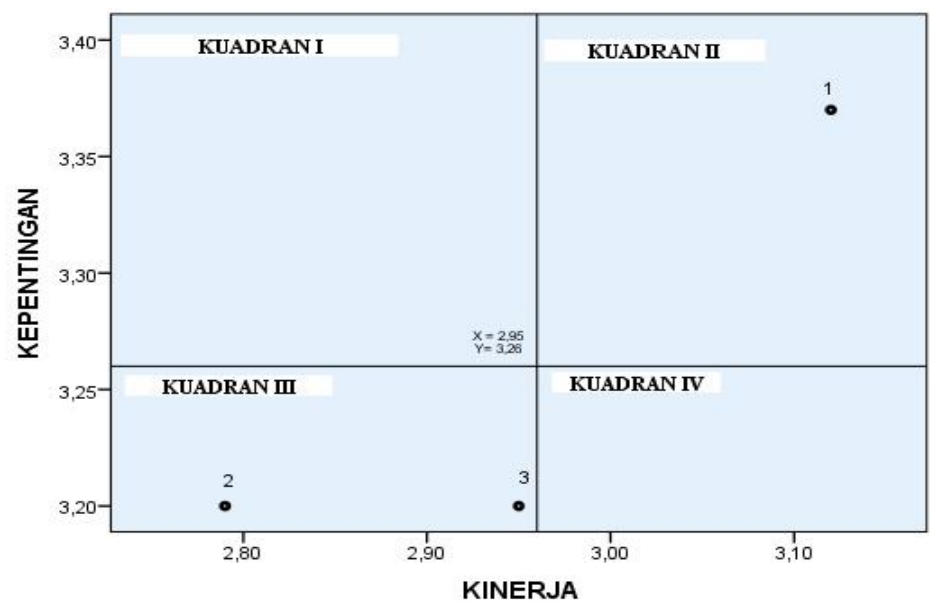

Gambar 4. Diagram kartesius jadwal dan jenis progam

Pada kuadran II (pertahankan prestasi), variabel yang termasuk didalamnya adalah kesesuaian kebutuhan dengan jenis program yang terrealisasi. Ini merupakan hal yang harus dipertahankan oleh pihak perusahaan untuk menunjang penyaluran program-program berikutnya. Variabel ini sangat penting dan kinerjanya sangat baik.

Kuadran III (prioritas rendah), dalam jadwal dan jenis program ada dua variabel yang harus ditingkatkan kinerjanya yaitu ketepatan waktu antara rencana pelaksanaan program dengan realisasinya dan kesesuaian antara jenis program yang direncanakan dengan yang terrealisasi. Peningkatan terhadap variabel ini dapat dipertimbangkan kembali pengaruhnya terhadap manfaat yang dirasakan masyarakat sangat kecil.

\section{d. Pendanaan program CSR}

Pendanaan program adalah pembiayaan yang dilakukan oleh pihak penyelenggara atau perusahaan berupa mesin kapal berukuran kecil yang diberikan kepada tiap masyarakat penerima program CSR untuk menjalankan kegiatan/program yang telah dibuat sesuai dengan pembagian kelompok atau individu.

Dari hasil penelitian yang dilakukan, didapatkan nilai rata-rata dari tingkat kinerja dan tingkat kepentingan disajikan pada tabel 3.

Tabel 3. Nilai rata-rata tingkat kinerja dan tingkat kepentingan

\begin{tabular}{|c|c|c|}
\hline No & Nilai rata-rata tingkat kinerja & Nilai rata-rata tingkat kepentingan \\
\hline 1 & 2,87 & 3,00 \\
\hline 2 & 3,16 & 3,29 \\
\hline
\end{tabular}

Sumber: Hasil Penelitian, 2016 


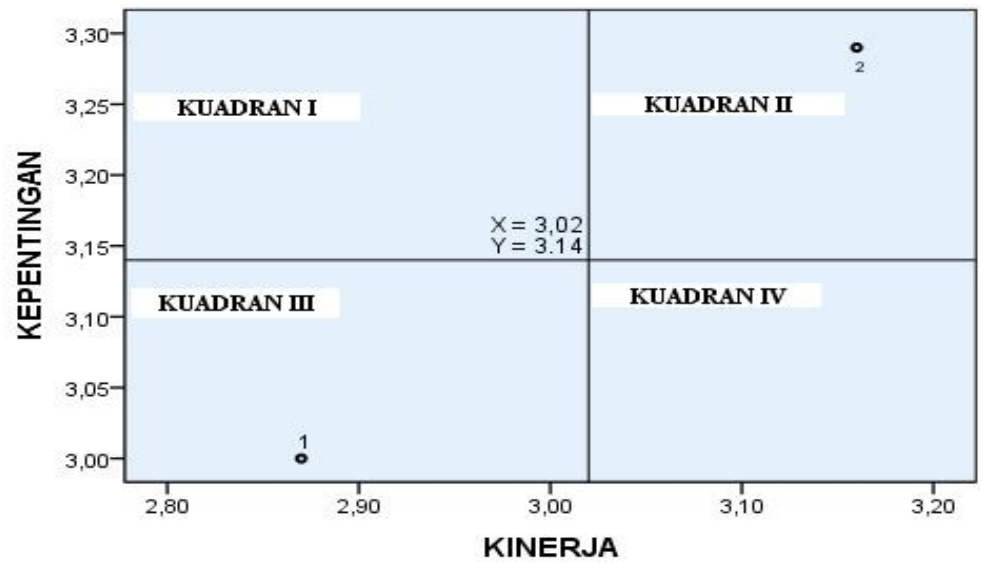

Gambar 5. Diagram kartesius pendanaan program CSR

Variabel ini masuk dalam kuadran III (prioritas rendah) dimana variabel ini harus lebih ditingatkan kinerjanya sehingga variabel ini masih dapat dipertimbangkan pengaruhnya. Kedua, ketepatan waktu turunnya dana dengan kebutuhan pendanaan masyarakat. Variabel ini termasuk dalam kuadran II (pertahankan prestasi). Menurut masyarakat ketepatan waktu pendanaan merupakan hal yang sangat penting dan harus dipertahankan oleh pihak perusahaan untuk meningkatkan kualitas program-program selanjutnya.

\section{e. Unsur Penunjang Program}

Unsur penunjang program adalah indikator-indikator pelengkap pada program CSR yang telah dirancang dengan terstruktur seperti mesin kapal yang diberikan kepada masyarakat Desa Tambea.

Dari hasil penelitian yang dilakukan di Desa Tambea, Kecamatan Pomalaa Kabupaten Kolaka didapatkan nilai rata-rata tingkat kinerja dan tingkat kepentingan yang bisa kita liat pada tabel 4.

Tabel 4. Nilai rata-rata tingkat kinerja dan tingkat kepentingan

\begin{tabular}{|c|c|c|}
\hline No & Nilai rata-rata tingkat kinerja & Nilai rata-rata tingkat kepentingan \\
\hline 1 & 3,12 & 3,29 \\
\hline 2 & 3,04 & 3,04 \\
\hline 3 & 3,12 & 3,12 \\
\hline 4 & 3,08 & 3,25 \\
\hline 5 & 3,08 & 3,20 \\
\hline
\end{tabular}

Sumber: Hasil Penelitian, 2016

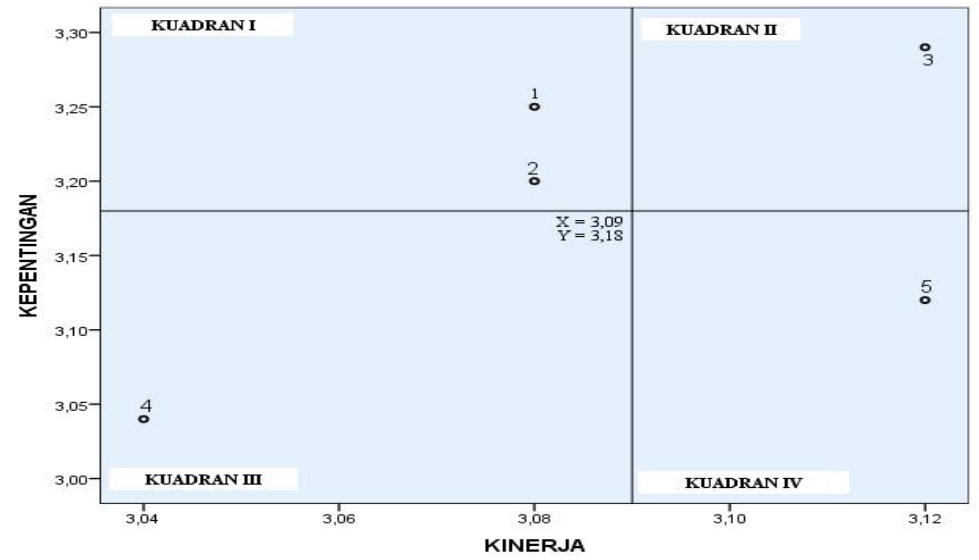

Gambar 6. Diagram kartesius unsur penunjang program 
CC Jounal publiuho is licensed under a Creative Commons Attribution 4.0 International License, which permits unrestricted use, distribution, and reproduction in any medium, provided the original work is properly cited.

Kuadran I (prioritas utama) terdapat dua variabel yang dianggap pentinng oleh masyarakat tetapi variabel tersebut memiliki tingkat kinerja yang belum sesuai dengan tingkat kepentingan masyarakat. Menurut masyarakat, perusahaan harus menggunakan sarana dan prasarana yang ada untuk meningkatkan tingkat kinerjanya.

Kuadran II (pertahankan prestasi), keberadaan peralatan/perlengkapan pelaksanaan program harus dipertahankan karena masyarakat sangat membutuhkan peralatan/perlengkapan untuk menunjang kegiatan masyarakat sehingga variabel ini akan dipertahankan untuk waktu selanjutnya.

Kuadran III (prioritas rendah), keberadaan fasilitator sebagai penunjang program. variabel yang termaksud dalam kuadran ini harus di pertimbangkan kembali pengaruhnya terhadap manfaat yang dirasakan oleh masyarakat sangat kecil.

Kuadran IV (berlebihan), merupakan hal yang tingkat kinerjanya terlalu tinggi namun tingkat kepentingannya rendah sehingga menurut masyarakat variabel keberadaan mitra kerja pelaksanaan yang ditunjuk sebagai penunjang progam hanya menyebabkan terjadinya pemborosan sumber daya.

\section{KESIMPULAN}

Berdasarkan Hasil penelitian ini menunjukkan bahwa perusahaan PT. ANTAM Tbk UBPN SULTRA masih harus melakukan peningkatan terhadap unsur penyaluran program dan unsur penunjang program dimana kedua unsur ini masih memiliki variabel-variabel yang berlebihan dan dianggap sebagai pemborosan sumber daya.

\section{DAFTAR PUSTAKA}

D. A. Setyaningrum, "Pengaruh Implementasi Corporate Social Responsibility Terhadap Kesejahteraan Hidup Masyarakat ( Studi Kasus Pada Pt . Apac Inti Corpora , Bawen ). Skripsi. (2011), 20-21.

Djunaedi, R. R., Baga, L. M., \& Krisnatuti, D, Efektivitas Implementasi Corporate Social Resposibility Pt. ABC, Jurnal Aplikasi Bisnis Dan Manajemen, I (2), Vol. I, (2015), 4-5.

Fashlia Maharani H. Rusdi, Persepsi Masyarakat Tentang Implementasi Program CSR (Corporate Social Responsibility) Pasca Tambang Perusahaan Pt. Aneka Tambang Di Desa Kacepi Kecamatan Pulau Gebe Kabupaten Halmahera Tengah. Skripsi. (2016), 16.

Jorgie Aditya Prawira, Pengaruh Pelaksanaan Program Kemitraan Csr Pt. Antam Terhadap Kemandirian Pelaku Usaha Kecil Dan Menengah Di Kabupaten Kolaka Sulawesi Tenggara. Skripsi. (2015), 30.

J. 0. Ong And J. Pambudi, Importance Performance Analysis Di SBU Laboratory Cibitung Pt Sucofindo ( Persero ), Vol. IX, No. 1, 3-4. 